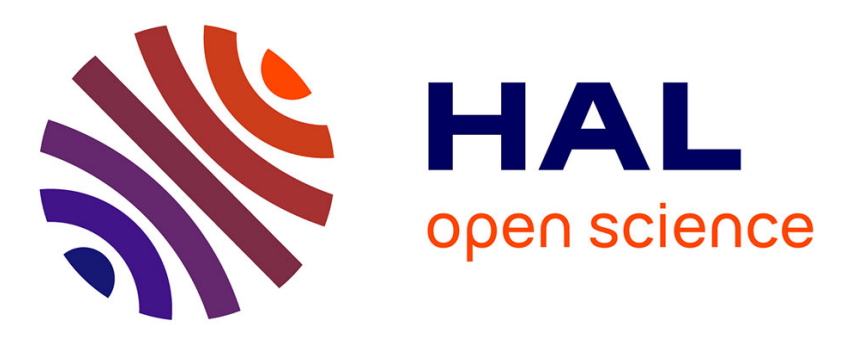

\title{
Financial Shortfall for Electric Vehicles: economic impacts of Transmission System Operators market designs
}

Paul Codani, Yannick Perez, Marc Petit

\section{- To cite this version:}

Paul Codani, Yannick Perez, Marc Petit. Financial Shortfall for Electric Vehicles: economic impacts of Transmission System Operators market designs. Energy, 2016, 113, pp.422-431. 10.1016/j.energy.2016.07.070 . hal-01346860

\section{HAL Id: hal-01346860}

https://hal-centralesupelec.archives-ouvertes.fr/hal-01346860

Submitted on 19 Mar 2018

HAL is a multi-disciplinary open access archive for the deposit and dissemination of scientific research documents, whether they are published or not. The documents may come from teaching and research institutions in France or abroad, or from public or private research centers.
L'archive ouverte pluridisciplinaire HAL, est destinée au dépôt et à la diffusion de documents scientifiques de niveau recherche, publiés ou non, émanant des établissements d'enseignement et de recherche français ou étrangers, des laboratoires publics ou privés. 


\title{
Financial Shortfall for Electric Vehicles: economic impacts of Transmission System Operators market designs
}

\author{
Paul Codani ${ }^{\mathrm{a}, *}$, Yannick Perez ${ }^{\mathrm{a}, \mathrm{b}}$, Marc Petit $^{\mathrm{a}}$ \\ ${ }^{a}$ Group of Electrical Engineering Paris (GeePs), UMR CNRS 8507, CentraleSupelec, UPSud, \\ UPMC, Gif-sur-Yvette, France \\ ${ }^{b}$ RITM Lab, University of Paris-Sud, Orsay, France
}

\begin{abstract}
Using electric vehicles as transmission system operator reserve providing units has been demonstrated as being both a feasible and a profitable solution. However, the surveys leading to these conclusions are always conducted either without considering the transmission system operator market rules, or using the existing ones from the local system operator. Nevertheless, such rules have potentially a great impact on the electric vehicles' expected revenues, and they are likely to change within the next few years. This paper aims to assess how these rules impact the ability for electric vehicles to provide power reserves and on their expected remuneration for doing so. First, a list of the most important market rules for this use case is drawn up. Then, a simulation model is developed in order to evaluate the expected revenues for the electric vehicles. Finally, these expected revenues are computed considering various combinations of rules. A loss of revenue for electric vehicles is identified, due to the use of non-optimal rules governing grid services remuneration. Considering the French case, according to the simulation results, this financial shortfall per vehicle and per year ranges from $193 €$ to $593 €$. Market design recommendations for reserve markets are deduced from these results.
\end{abstract}

Keywords: Electric Vehicles; Frequency control; Vehicle-to-Grid; Regulation; Economics

\section{Introduction}

In order to cope with the objectives of reductions in $\mathrm{CO} 2$ emissions in both electricity grids and transportation systems, governments' environmental-friendly

\footnotetext{
${ }^{*}$ Corresponding author:

Email address: paul.codani@centralesupelec.fr (Paul Codani)
} 
policies tend to incentivize the use of alternative fuels for propelling vehicles. Among the possible technical options, plug-in vehicles (EVs) driven by electric motors and powered by electrochemical batteries represent a promising solution. As a consequence, an increasing number of car manufacturers now have plug-in hybrid and fully electric vehicles in their product lines and EV sales are expected to increase significantly within the next few years [1].

However, EV sales are not yet following their expected trend: for instance in December 2015, the EV market share only reached $1.2 \%$ in France [2], and the initial forecast of having 2 million EVs on the roads by 2020 has been downgraded to 500,000 [3]. EV sales are increasing slowly for three main reasons: (a) the limited EV driving ranges compared with their equivalent in conventional vehicles; (b) the lack of charging infrastructure; and (c) their relatively high price [4].

One suggested way to deal with the latter issue is to use EVs as distributed storage units when they are plugged-in - in France, this entails more than $95 \%$ of the time [5] - turning them into so-called Grid Integrated Vehicles (GIVs). Such a GIV has a means of communication, a controllable charging rate, and, in this case, is able to supply Vehicle-to-Grid power, i.e. to inject power back to the grid. Under these conditions, GIVs participate in the grid system's wide balance between production and demand; they are active components of the smart grids, in which demand becomes more controllable and able to follow the generation patterns.

According to the literature, the most profitable solution is the integration of EVs into Transmission System Operator (TSO) ${ }^{1}$ reserves [6] - mainly to provide frequency regulation reserves. In this case, a fleet of GIVs is controlled by and reports to a central aggregator, which is responsible for presenting the fleet as a single entity in the frequency control market.

This solution has been intensively studied in the scientific literature, both from a technical and an economic point of view. Complex multi-objective optimization problems were proposed, solving linear [7] or quadratic problems [8]. Economic earnings were evaluated for various areas such as Germany [9] or PJM area in the United Stated [6], sometimes taking battery degradation into account [10]. Similarly, there are several ongoing demonstration projects, in particular in the USA (California, Delaware) and in Europe (Denmark) [11]. These theoretical papers bear little consideration for the rules and regulations of the targeted electricity market: they are either ignored in the case of technical surveys, or considered as given in most economic studies. However, there is a wide diversity of electricity market rules and regulations across the world and even within Europe, mainly because TSOs face different technological and economic challenges, and have different

\footnotetext{
${ }^{1}$ In the United States, TSOs are referred to as Independent System Operators (ISOs)
} 
topologies and energy mixes [12]. Moreover, with the liberalization of electricity markets, TSO market rules are likely to evolve within the next few years in order to better support the three main energy policy pillars of the European Union (EU): security of supply, sustainability, and competitiveness.

Thus, in a smart grid environment, electromobility could be a promising solution not only to reduce local air pollution, but also to manage intermittent distributed generation (DG). For instance, reference [13] shows how solar and wind sources could be coupled with EV charging load curves in France at the regional scale. It has also been demonstrated that lowest costs and best voltage profiles were achieved in power distribution networks by combining various DG sources with EVs [14]. Similar conclusions are found at the system-wide scale [15]. However, in order to achieve this potential future, integrated grids require adapted technical and regulatory structures that are not complete yet. Electricity grids, and hence their regulatory frameworks, have a key role to play in facilitating this transformation from vertically integrated systems to the emergence of new actors, services, and storage technologies. In this work, the authors analyze the regulatory changes that are required to align grid needs with grid users' incentives in order to promote the development of electromobility.

More specifically, the authors assess the economic impacts of the implemented market rules and regulations on the expected revenues of a fleet of GIVs providing frequency regulation. In order to do so, the existing frequency regulation rules from six TSOs are reviewed and a 'best combination' of existing rules with respect to this solution studied is presented. Then, a simulation model which was developed in a previous work is implemented [16]. This model is applied for two different sets of market rules; the first one represents the current French rules, while the second one is the aforementioned 'best combination'. The simulation results are used to infer frequency control market design recommendations.

In this paper, the authors work from the perspective of EV car owners; the expected revenues are entirely intended for them. The aggregator is assumed to be a benevolent third party; obviously, in real life, the aggregator should earn something out of these revenues, but addressing business models is beyond the scope of this paper.

The paper is organized as follows. Section 2 presents the survey of the TSO rules. In section 3, the simulation model is recalled and the data used are described. Section 4 features and discusses the simulation results under two combinations of rules: a best case and the current French rules. Policy considerations are inferred from these results in section 5 . 


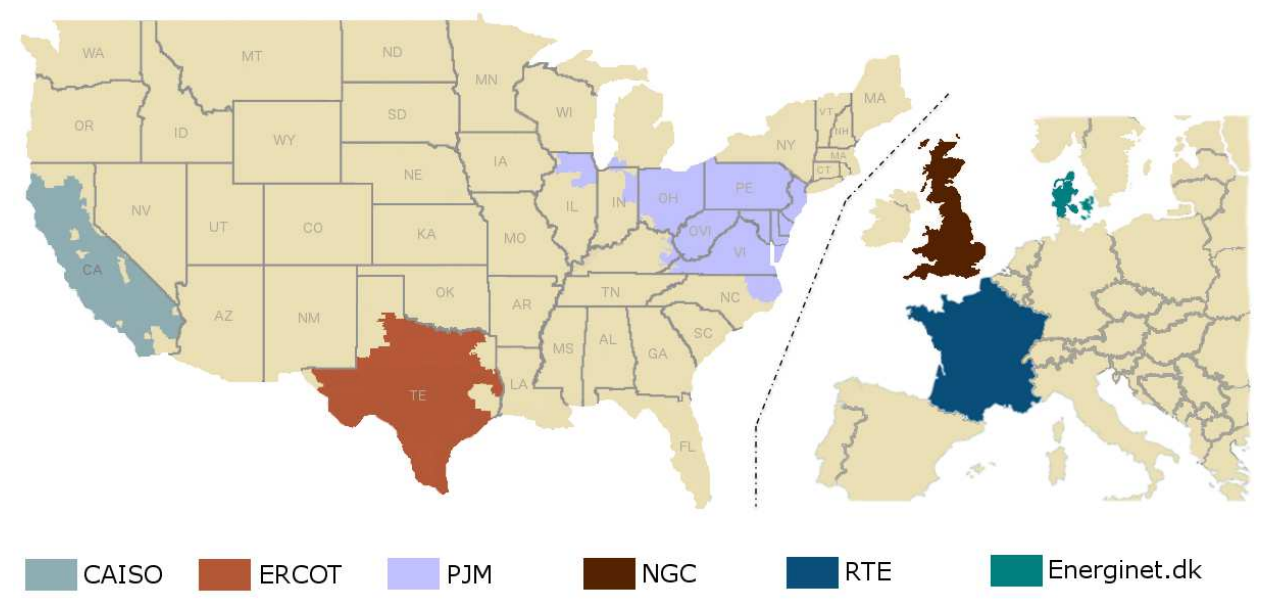

Figure 1: Maps of the six TSOs understudy

\section{TSO rules survey}

Six TSOs are compared by screening their manuals on a list of rules and characteristics that are important for GIV deployment. The six TSOs in question, represented in Figure 1, are: Energinet.dk (Denmark), RTE (France), ERCOT (Texas, USA), CAISO (California, USA), PJM (North-East, USA), and NGC (UK). The associated regulatory manuals are [17], [18, 19, 20], [21, 22, 23, 24, 25], [26, 27, 28, 29], [30, 31, 32, 33] and [34, 35, 36].

Based on the findings from this analysis, and on feedback from the GridOnWheels [37] and Nikola [38] demonstration projects, two essential and relevant sets of rules (hereafter called modules) that assemble the critical regulation for enabling the participation of GIV fleets to grid services are identified: the rules presiding over the aggregation of GIVs, and the rules establishing the payment scheme of the services provided by GIVs. The objective of this approach is to finally be able to determine a 'best combination' of frequency control rules for GIV fleets based on the authors' opinions and on the point of views of researchers involved in the aforementioned demonstration projects. The two modules are described in more detail in the two following subsections. 


\subsection{Module 1: the rules governing the aggregation of Electric Vehicles}

An aggregator ${ }^{2}$ has a key role in the organization enabling the provision of TSO services by GIV: it is in charge of presenting a GIV fleet as a one and only body to the TSO. Aggregators are necessary for the following reasons: (a) TSOs are used to treating with large entities, (b) TSOs do not have the information processing abilities to control numerous $\mathrm{kW}$ size units; they were thought up for a few multiMW size power plants, and (c) TSOs count on reliable resources, which is an issue for a unique GIV. Transportation remains the priority for GIV, but from the grid viewpoint, one GIV is likely to unplug at any time. Aggregators are able to deal with these matters by supervising a huge amount of GIVs [39] and presenting a unique, statistically-reliable entity to the TSO.

On the other hand, such GIV coalition should be made possible by TSO rules. Here, three main rules are underlined: the smallest bidding size allowed in the market, the possibility to aggregate across several Distribution System Operators (DSOs), and the technical level of aggregation.

\subsubsection{Minimum bidding size}

All TSO markets require bids to have a minimum size [40]; throughout this analysis, a spectrum of least bid from $100 \mathrm{~kW}$ to $10 \mathrm{MW}$ was observed. As far as GIV aggregations are concerned, this minimum-bidding value leads to a minimum number of GIVs. A substantial minimum bidding value would be a challenge for the development of pilot and early commercial projects, since the GIV fleet in question may miss some vehicles to meet the requirement.

As an example, considering electric vehicle supply equipments (EVSE) of $3 \mathrm{~kW}$, and a GIV availability factor of one third for grid services' markets, 100 GIV would be required to meet a minimum bid value of $100 \mathrm{~kW}$. However, if this minimum was set to $10 \mathrm{MW}, 10,000 \mathrm{GIV}$ would then be needed. Comparing these results with those of today's EV sales (there are approximately 50,000 EVs in France [2]) shows that making an aggregation of private electric vehicles in France would be extremely difficult ${ }^{3}$.

Even if EV penetration was more important, a significant minimum bidding value would restrict the variety of possible aggregators: for instance, company fleets would not be admitted as aggregators.

\footnotetext{
${ }^{2}$ An aggregator is typically a third party entity, but different stakeholders could fulfill its role: System Operators, utility companies, car OEMs, etc.

${ }^{3}$ Note that the geographical location of the EVs bears little importance here as the frequency value is the same at each node of the network.
} 


\subsubsection{Possibility to aggregate across DSOs}

The possibility to aggregate GIV across multiple DSO technical areas is also a major concern for aggregators. GIVs can potentially change their location, and they may be spread across several DSO zones ${ }^{4}$. This problem is all the more important that there are numerous DSOs working with one TSO: reference [41] shows that some TSOs work mainly with a single DSO (as in France, where ERDF is responsible for $97 \%$ of the distribution grid), but some others work with many DSOs (there are, for example, more than 850 DSOs in Germany). Not being able to aggregate across DSOs when there are so many of them would make aggregation almost unfeasible. The most favorable option is therefore to allow such cross-DSO aggregation.

More broadly speaking, according to [42], an extended cooperation between the DSOs and the TSOs will be necessary to ensure a cost-efficient integration of Distributed Energy Resources (DERs) in the future, and this is in particularly true for GIVs.

\subsubsection{Operational versus financial-only aggregation}

Finally, a difference between operational and financial-only aggregations should be made. The best form of aggregation is the operational one; it makes it possible to combine bids and then for a central aggregator to directly control distributed power flows. In other words, the aggregator may deaggregate the TSO request among its units as it wish. In a financial-only aggregation, aggregators are only allowed to merge financial bids, but the deaggregation of the TSO request is not at the sole discretion of the aggregator, it is bound by the individual offers of each unit.

Table 1 summarizes the main findings for this module. For each rule, the best and the most restrictive applications that were observed throughout the TSO analysis are indicated.

\subsection{Module 2: the rules governing the remuneration scheme}

The provision of grid services by GIVs is a mean to lower the total cost of ownership (TCO) of EVs. Indeed, the GIV fleet will earn revenues from its participation in the frequency control market. As a consequence, the payment scheme of these grid services is of paramount importance. GIVs should be remunerated in a fair manner, and from an economic perspective, this remuneration should at least cover the induced costs. Such costs include battery degradation and hardware and software investments. They are beyond the scope of this paper.

\footnotetext{
${ }^{4}$ Registering EVSE rather than GIV may settle the issue of locational shift, but EVSE would still be spread across various DSOs.
} 
Table 1: The Different Organizations for Module 1

\begin{tabular}{lll}
\hline & Organization & \\
\cline { 2 - 3 } Rule & Best Option & Restrictive Option \\
\hline R1: Minimum size & $100 \mathrm{~kW}$ & $10 \mathrm{MW}$ \\
R2: Aggregation across DSO & Possible & Impossible \\
R3: Aggregation level & Operational & Financial \\
\hline
\end{tabular}

\subsubsection{Remuneration scheme: regulated or market based}

TSOs have several means at their disposals to dispatch the power among the units that are participating in a grid service. The two main ways of doing so are proceeding through open markets or through regulated contracts [43]. In the former solution, participating units may bid in the market as they wish. A bid is typically consisted of a capacity and its price. Depending on its needs, the TSO will then accept all or part of the bids. This approach ensures transparency in the dispatch process. In the latter solution, the dispatch method differs from one unit to the other, as each unit has its own contract with the TSO. For instance, some TSO base the amount of capacity to be provided by a particular unit on its historical load share.

Auction markets are much more appropriate than regulated approaches for new innovative units such as GIV. Regulated approaches are very lengthy to change; however, quick regulatory adaptations are required to integrate new resources. Furthermore, considering a GIV fleet, some vehicles are likely to join and leave the coalition at any moment; as a consequence, a fixed bilateral contract might turn out to be very constraining for an aggregator.

\subsubsection{Imperfection of the remuneration scheme}

It is striking to point out grid services that are mandatory but not remunerated by some TSOs. For instance, PJM and CAISO do not pay for primary frequency control. In this case, participating in primary frequency control is mandatory for all power plants, which have to bear the costs of providing this control mechanism.

The more imperfect the remuneration scheme and the less it compensates the services provided, the less GIV fleets are able to recover the value of their flexibility. In the 'best combination' of rules for GIVs, all existing services are necessarily remunerated.

On the other hand, TSOs could also benefit from improving and completing their remuneration scheme. Indeed, units which have to compulsorily provide services without getting paid perform usually poorly. For example, the provision of 


\footnotetext{
${ }^{5}$ Many island networks are isolated, i.e. they are connected to other networks only through DC lines.
}

primary frequency control in the US has significantly deteriorated throughout the years [44], arising security concerns.

\subsubsection{Additional financial bonus for extreme flexibility}

According to the Federal Energy Regulatory Commission (FERC), present remuneration methods for TSO grid services are unfair and discriminatory [45]. This is particularly due to the fact that fast ramping units (units that have the ability to adapt their power setpoint rapidly) are not compensated enough considering the bigger quantity of reserve capacity they supply in a brief moment in comparison with slow-ramping units.

The FERC suggests ways to address this issue. First, all MWh that are actually exchanged between the grid and a unit for grid service purposes should be considered in absolute value as a source of positive revenue for the unit, no matter the flowing direction of the MWh. This implies that remuneration schemes include a utilization component (in $\$ / \mathrm{MWh}$ ) in addition to the traditional availability component (in \$/MW). Fast ramping units supply more MWh than slow ramping ones, thus their remuneration would be higher with the suggested payment scheme. Moreover, the FERC suggests that accuracy and response time should be taken into account in the payment calculation method [45], what would be beneficial to fastramping resources.

GIV are able to adjust their power very quickly [46]. As a consequence, GIV fleets achieve better earnings if such financial bonus is implemented by the TSO.

Another option would be to consider fast and slow ramping bids as two separate products. A market dedicated to the trading of fast ramping bids only would be created, with its own remuneration scheme which would be more adapted to fast ramping units.

Finally, most of today's electrical grids are highly interconnected, and thus may not feel an urgent need for fast-ramping products. Rather, in a first time, such products may be of particular interest in case of extreme disturbances on the grid. Then, as unpredictable and intermittent renewable sources' penetration increases, more and more flexibility means will be required to balance production and demand: fast ramping units may become a necessity. This has already been noted in island grids, which are very responsive to grid disturbances ${ }^{5}$ as, for instance, in the Danish island of Bornholm [47].

Table 2 summarizes the main findings concerning the remuneration scheme, and the various organizations observed. As for Table 1, the options presented in 
this table were identified by means of the TSO rules analysis.

Table 2: The Different Organizations for Module 2

\begin{tabular}{|c|c|c|}
\hline \multirow[b]{2}{*}{ Rule } & \multicolumn{2}{|l|}{ Organization } \\
\hline & Best Option & Restrictive Option \\
\hline $\begin{array}{l}\text { R4: Nature of the remu- } \\
\text { neration }\end{array}$ & Market Based & Regulated \\
\hline $\begin{array}{l}\text { R5: Imperfection of the } \\
\text { remuneration }\end{array}$ & $\begin{array}{l}\text { All grid services should be } \\
\text { remunerated }\end{array}$ & $\begin{array}{l}\text { Incomplete payment } \\
\text { scheme }\end{array}$ \\
\hline $\begin{array}{l}\text { R6: Financial bonus for } \\
\text { extreme flexibility }\end{array}$ & $\begin{array}{l}\text { Set at the efficient level, or } \\
\text { separate market created }\end{array}$ & Not Existing \\
\hline
\end{tabular}

\subsection{Partial conclusion}

Two sets of rules were identified, leading to different forms of organization. A best case, a worst case, and some intermediate cases can now be defined. Table 3 sums up the findings for both modules and for all TSOs ${ }^{6}$. A wide diversity of TSO rules is observed.

To go one step further, the financial shortfall for GIVs when a 'bad' combination of rules is implemented should be evaluated and quantified, in comparison with the 'best combination' for GIVs. In order to do so, a simulation model which will enable to assess the expected GIV revenues needs to be developed.

\section{Simulation Model}

In this section, the basics of the simulation model used to assess the economic revenues of the GIV fleet are recalled; this model has already been described in a previous work [16]. In section 2, the most important rules for GIVs providing TSO services were identified; in order to perform an economic evaluation, a particular TSO service market has to be selected. The present analysis focuses on the primary frequency control (see 3.1) market. It is worth noting that GIVs could provide TSOs with other grid services, such as secondary frequency control, balancing mechanisms, etc. This work focuses on primary frequency control because: (a) GIVs are very fast responding units, and the aforementioned demonstration

\footnotetext{
${ }^{6}$ The TSO manuals were analyzed during the years 2013-2014. Some of the rules may have changed since then; however, the overall rationale of this analysis and how it is used to compare various TSO regulatory frameworks remains valid.
} 
Table 3: Summary of the identified rules for each TSO understudied ${ }^{\mathrm{a}}$

\begin{tabular}{|c|c|c|c|c|c|c|}
\hline \multirow[b]{2}{*}{ Rule } & \multicolumn{6}{|l|}{ TSO } \\
\hline & CAISO & ERCOT & $P J M$ & $N G C$ & $R T E$ & Energinet.dk \\
\hline R1 & $0.5 \mathrm{MW}$ & $0.1 \mathrm{MW}$ & $0.1 \mathrm{MW}$ & $10 \mathrm{MW}$ & $1 \mathrm{MW}$ & $0.3 \mathrm{MW}$ \\
\hline $\mathbf{R 2}$ & Not Possible & Not Possible & Not Possible & Possible & Possible & Possible \\
\hline $\mathbf{R 3}$ & Financial & Financial & Operational & Operational & Operational & Operational \\
\hline R4 & $\begin{array}{l}\text { Market } \\
\text { based }\end{array}$ & $\begin{array}{l}\text { Market } \\
\text { based }\end{array}$ & $\begin{array}{l}\text { Market } \\
\text { based }\end{array}$ & $\begin{array}{l}\text { Market } \\
\text { based }\end{array}$ & Regulated & $\begin{array}{l}\text { Market } \\
\text { based }\end{array}$ \\
\hline R5 & $\begin{array}{l}\text { Incomplete } \\
\text { payment } \\
\text { scheme }\end{array}$ & $\begin{array}{l}\text { Incomplete } \\
\text { payment } \\
\text { scheme }\end{array}$ & $\begin{array}{l}\text { Incomplete } \\
\text { payment } \\
\text { scheme }\end{array}$ & $\begin{array}{l}\text { Incomplete } \\
\text { payment } \\
\text { scheme }\end{array}$ & $\begin{array}{l}\text { All AS are } \\
\text { remunerated }\end{array}$ & $\begin{array}{l}\text { All AS are } \\
\text { remunerated }\end{array}$ \\
\hline R6 & Yes & No & Yes & No & No & No \\
\hline
\end{tabular}

${ }^{a}$ Rules as they were in 2013 - 2014. Some of the rules may have changed since then, what would not change the rationale of the present work.

projects proved GIV fleets capable of providing primary control from a technical perspective [48]; (b) primary frequency control induces solicitations which are averagely null in energy, as shown below in Figure 4, which is very interesting from an EV perspective; (c) market clearing periods can be very short (down to an hour) for this service, which is also very interesting for a GIV fleet.

\subsection{Primary frequency control}

The analysis focuses on the provision of primary frequency control by Grid Integrated Vehicles (GIV). The grid frequency continuously oscillates around its nominal value (50Hz in Europe). Transmission System Operators (TSO) are responsible for ensuring that the frequency deviations do not exceed a predefined range. As electricity is produced by synchronous machines, the frequency - linked to the generator's mechanical speed - mirrors the real time equilibrium between production and demand. If the mechanical power produced by the power plants' turbines exceeds the electricity power demand, the frequency will get over its nominal value and inversely. Consequently, TSOs manage the frequency by means of three control levels, which aim to balance production and demand in real time.

The first level is called primary frequency control. Its objective is to end the frequency divergence, but the frequency does not retrieve its original value. Primary reserve units read the frequency value by themselves, and adapt their power output to this measurement and according to specific rules [16]. References [49] 


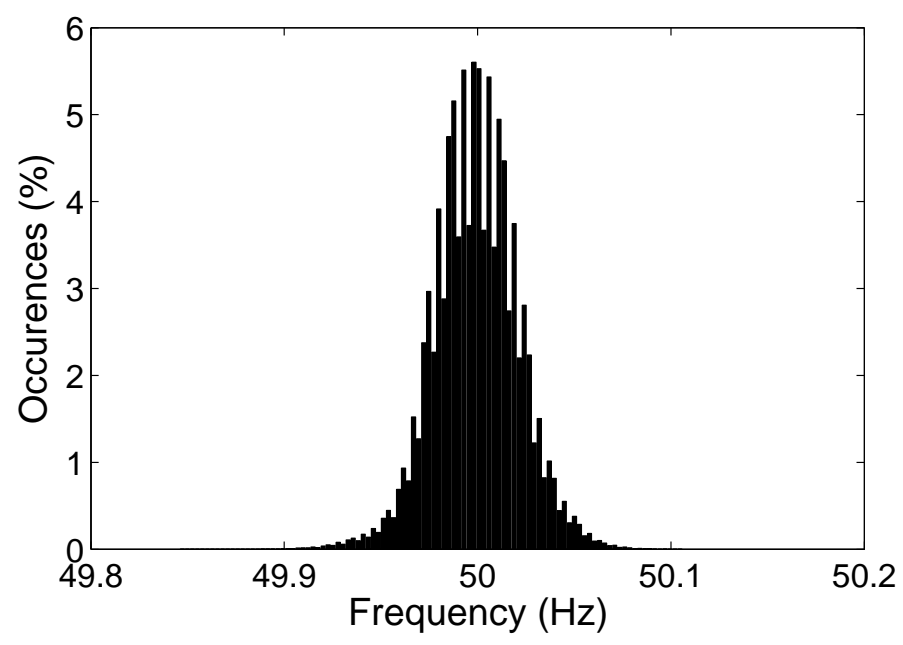

Figure 2: Distribution function of the frequency recording

and [50] provide more details about frequency control mechanisms from technical and economic perspectives, respectively.

A full month of frequency data was recorded at CentraleSupelec in April 2014 by means of a frequency meter. These measurements abide by ENTSO-E (European Network of Transmission System Operators for Electricity) requirements, i.e. they have a resolution better than $10 \mathrm{mHz}$ and the frequency evaluation period is 1s. A summary of the frequency data set characteristics is provided in Table 4, and Figure 2 displays the distribution function of the recording used. In order to check the consistency of these measurements, their characteristics were compared over the same period of time with those of the RTE data set available on the RTE website [51] (which only has a 10-second time stamp, and this is it was not satisfactory for the present simulations).

The two data sets turn out to have very similar characteristics. In particular, the frequency is contained in the interval $[49.95 \mathrm{~Hz} ; 50.05 \mathrm{~Hz}] 97 \%$ of the time; within this interval, primary reserve units should provide less than $25 \%$ of their reserve.

The main limitation of the frequency recording is that it only covers one month of frequency variations; some more extreme events could have happened during the year. Moreover seasonal effects, which are not represented in this data set, might have an impact on frequency variations.

\subsection{GIV fleet}

The EV fleet model is the same as in [16]. Here, the main hypothesis are recalled, please refer to [16] for the complete justifications. All GIV are assumed 
Table 4: Main characteristics of the frequency data set used, and comparison with RTE measurements

\begin{tabular}{lccc}
\hline Criteria & Author data set & RTE data set & Difference (\%) \\
\hline Mean $(\mathrm{Hz})$ & 50 & 50 & $-0,002$ \\
Std $(\mathrm{Hz})$ & 0,02 & 0,02 & 0,4 \\
Min $(\mathrm{Hz})$ & 49,9 & 49,9 & $-0,01$ \\
Max $(\mathrm{Hz})$ & 50,1 & 50,1 & 0 \\
$\mathrm{P}(49,95<\mathrm{f}<50,05)$ & 0,97 & 0,97 & $-0,22$ \\
\hline
\end{tabular}

to have a $22 \mathrm{kWh}$ battery. The state-of-charge (SOC) is kept within the range $0.2<$ $S O C / S O C_{\max }<0.9$ in order not to get to extreme SOC values, which could lead to significant battery degradation (such phenomenon is observed at the cell level [52] and may then be extended at the battery level [53]). All GIV are supposed to be able to provide Vehicle-to-Grid (V2G) power, i.e. to inject power back to the grid.

GIV have the opportunity to charge during the night, with their primary EVSE, or at work during the day with their secondary EVSE. As the availability of charging stations at workplaces in the future is very uncertain, four scenarios are built, which are detailed in Table 5.

Table 5: The four scenarios for secondary EVSE penetration levels

\begin{tabular}{lc}
\hline Scenarios & Ratio of GIVs having an EVSE at work \\
\hline Scenario 1 & $0 \%$ \\
Scenario 2 & $25 \%$ \\
Scenario 3 & $50 \%$ \\
Scenario 4 & $75 \%$ \\
\hline
\end{tabular}

The available charging power values and their associated penetration levels at home and work places are summarized in Table 6.

The GIV trip characteristics are based on several references: internal PSA Groupe data, ministerial surveys [5] and demonstration project results [54]. The data used are very consistent with the real French transportation habits; the ministerial survey was built upon more than 35,000 observations. Similarly, PSA Groupe data are very representative of their users. Demonstration project results were used 
Table 6: Breakdown of Primary and Secondary EVSEs by Charging Technology Type

\begin{tabular}{lcc}
\hline Charging level & Primary EVSE & Secondary EVSE \\
\hline Slow charging A (3kW) & $95 \%$ & $35 \%$ \\
Slow charging B (7kW) & $5 \%$ & $34 \%$ \\
Intermediate charging (22kW) & $0 \%$ & $29 \%$ \\
Fast charging (43kW) & $0 \%$ & $2 \%$ \\
\hline
\end{tabular}

to check the consistency of the different data set, and to have real life energy consumption values. The GIV fleet model is stochastic and dynamic: each GIV has its own trip characteristics, which differ from one day to the other. GIV average distance trips (D), departure time $\left(\mathrm{T}_{d}\right)$, daily number of trips $(\mathrm{N})$ and seasonal energy consumption (E) are provided in Table 7. As GIVs are only used for the daily commuting trips, there are two trips a day for each GIV. D and $\mathrm{T}_{d}$ are distributed according to Gaussian distributions with mean $\mu$ and standard deviations $\sigma$.

Table 7: Trip-related models and parameters

\begin{tabular}{lll}
\hline Trip data & Model & Parameter values \\
\hline Daily trip numbers & Steady value & 2 \\
Trip distances & $d \sim \mathcal{N}\left(d_{\text {data }} ; \sigma_{d}\right)$ & $\mathrm{d}_{\text {data }}:$ internal use \\
& & $\sigma_{d}: 5 \mathrm{~km}$ \\
Departure times & $t \sim \mathcal{N}\left(t_{\text {mean }} ; \sigma_{t}\right)$ & $\begin{array}{l}\mathrm{t}_{\text {mean }}: \text { Best adapted to usual } \\
\text { commuting trips }\end{array}$ \\
& & $\sigma_{t}: 2$ hours \\
Consumption & Steady values & $\mathrm{c}_{\text {summer }} 129 \mathrm{Wh} / \mathrm{km}$ \\
& & $\mathrm{c}_{\text {winter }}=184 \mathrm{Wh} / \mathrm{km}$ \\
\hline
\end{tabular}

The advantage of the modeling approach considered here is that each GIV is modeled independently. Thus, extreme driver behaviors are taken into account by using probabilistic distribution functions. Similarly, the availability of each individual GIV is used to build the overall fleet availability (bottom-up approach). Many papers model GIV fleets as large single batteries [55], what makes it easier for computation, but less accurate with respect to the individual situation of each GIV. For instance, using a single battery model, it would not be possible to 
identify a GIV not capable of performing its next trip because it lacks energy for transportation, which is not satisfactory even if only one single GIV is concerned.

Obviously, covering only commuting trips in weekdays is not completely satisfactory. Future work should consist in enlarging the authors' databases in order to improve these routines. However, these trips can be considered as very representative since they account for most of the trips and kilometers driven in France [56], which makes them a good first basis for estimation.

\subsection{Aggregator's algorithm}

This part focuses on the aggregator's dispatch algorithm, which is used to dispatch the power among the GIV in real time. The operating principle, based on the one described in [39], is as follows:

1. At each market clearing period, each GIV $i$ computes its individual contribution for the coming market period $\mathrm{P}_{b i d_{i}}$, and communicates this value to the aggregator. The latter, by summing up all the individual GIV contributions, deduces the total fleet power available for frequency control $\mathrm{P}_{b i d}$ until the next market clearing period.

2. Then, within this period, the aggregator reads the frequency at each time stamp and, depending on the frequency value, calculates the power for frequency control that should be provided to the TSO $\mathrm{P}_{r e g}$ according to equation (1):

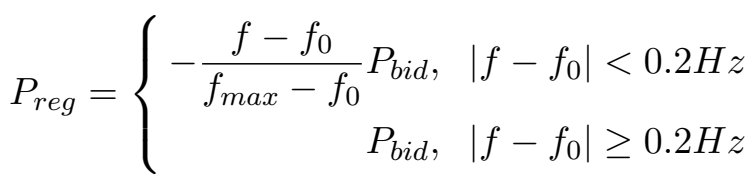

with $f$ the grid frequency, $f_{0}=50 \mathrm{~Hz}, f_{\max }=50.2 \mathrm{~Hz}, \mathrm{P}_{b i d}$ the power bid in the market, and $\mathrm{P}_{\text {reg }}$ the power actually provided for frequency control. This equation reflects the required response of primary reserve units to frequency deviations [57].

3. The aggregator computes a scaling factor $\mu=P_{r e g} / P_{b i d}$.

4. The aggregator sends to all GIVs their final individual contribution $\mu * P_{r e g_{i}}$.

5. Start back from point 1 for every new market clearing period (every hour), otherwise from point 2 .

Figure 3 pictures the various steps of the algorithm.

The calculation method of each individual GIV contribution (step 1) is based on the Preferred Operating Point (POP) of this vehicle, which is equivalent to the operating point of a traditional unit (such as a power plant); it represents the charging rate around which the GIV will provide frequency control. The POP calculation method is described in [16]. 


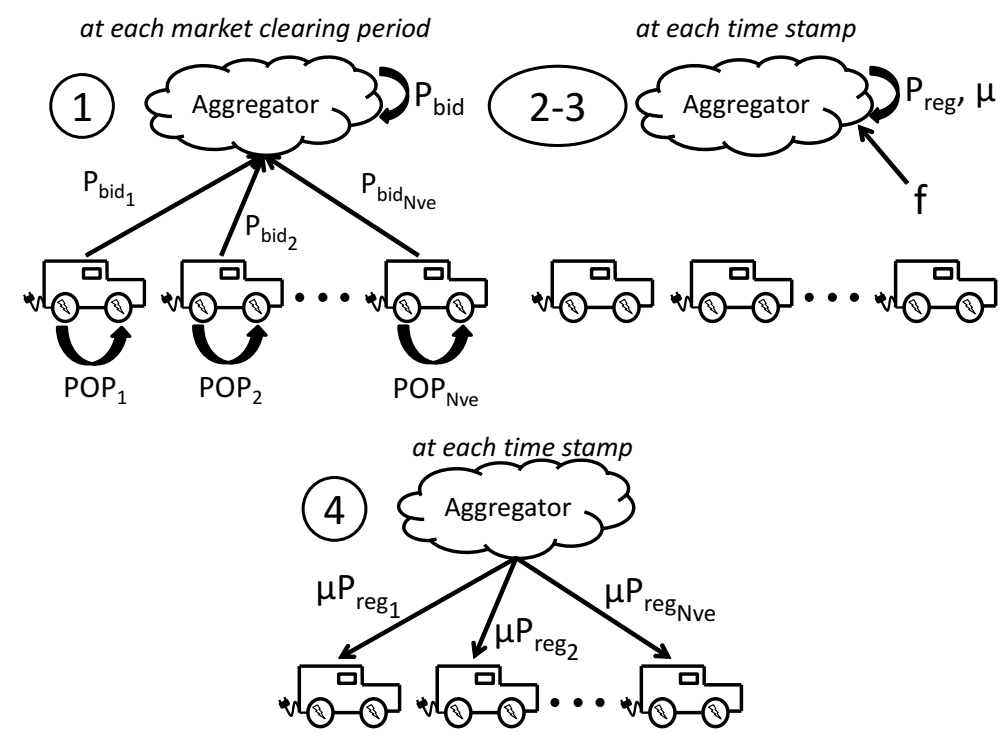

Figure 3: Dispatch algorithm operating scheme

The algorithm used here is a decentralized algorithm; as a consequence, it would be easily scalable to a large fleet of GIVs. Moreover, each GIV remains in control of its charging limits. Centralized algorithms perform slightly better in providing grid services, but computation time is much higher (thus they are much less scalable) and the entire decision process comes back to the aggregator.

\subsection{Simulation parameters}

For each EVSE power level, 100 simulations are run following the Monte Carlo approach for 100 GIVs. The simulations are performed with a one second time stamp over 5 week days. In order to compute the revenues, market prices from the Danish primary control market are used. They are provided on an hourly basis [58]. Five days of uninterrupted market prices as well as five continuous days of frequency values are arbitrarily selected from the data sets.

\section{Results and Discussions}

In this section, the results from simulations based on the model described in section 3 are provided, under two combinations of the rules that were detailed in section 2. First, the two selected combinations of rules are described and explained. Then, the results successively for the two use cases are provided. At last, 

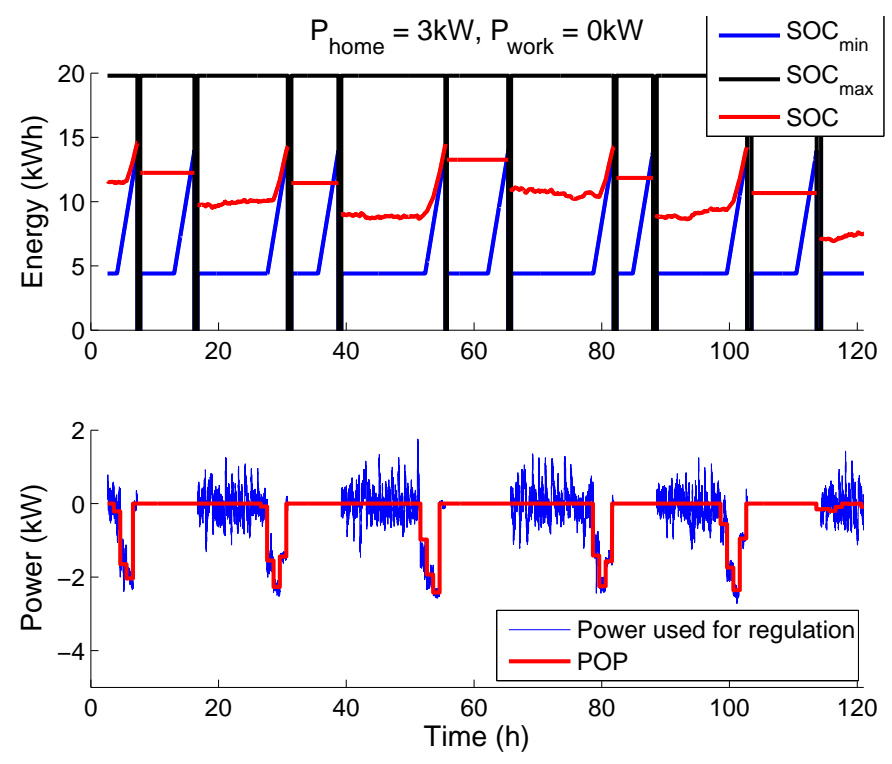

Figure 4: Simulation results for a single bidirectional capable GIV over 5 working days, with $P_{\text {home }}=3 \mathrm{~kW}$ and $P_{\text {work }}=0 \mathrm{~kW}$

the possible future evolutions of the rules are discussed by screening the ENTSOE (European Network of Transmission System Operators for Electricity) network codes.

But beforehand, as an example, Figure 4 displays some simulation results for a GIV whose home EVSE is able to deliver $3 \mathrm{~kW}$, and which does not have any EVSE at workplace. The impact of the POP is noticeable: when the SOC is getting too close to its lower limit $\left(\mathrm{SOC}_{\min }\right)$, the vehicle starts charging and always reaches its needs for transportation.

\subsection{Simulation use cases}

Based on the TSO analysis presented in section 2, two different representative combinations of rules are selected:

Combination A: this set of rules corresponds to the current French rules. Based on these rules, storage units are not allowed to participate in the frequency control market. RTE dispatches the required power among the production units, "based on their historical load share". In return, the latter are remunerated according to a fixed tariff amounting to $8.48 € / \mathrm{MW}$ for 30 minutes [19] (thus, there is no bonus for extra-flexibility). The minimum bidding size is 1MW. 
Combination B: this set of rules corresponds to the 'best combination' of rules for GIV fleets identified in section 2. Under this regulation, primary frequency control is organized via an hourly auction market. There is no barrier to new entrants, so GIV coalitions can compete like any other unit. Moreover, they receive a bonus for their extra-flexibility. In order to account for this financial bonus, the market prices from Energinet.dk are raised by 30\% (this percentage has been observed at the UD project where a bonus is implemented by PJM). The minimum bidding size is low $(100 \mathrm{~kW})$, enabling small fleets to participate in the market.

A simplistic view of these two combinations of rules is presented in Table 8 .

Table 8: Combinations of rules under study

\begin{tabular}{|c|c|c|}
\hline Rule & $\begin{array}{l}\text { Combination A: } \\
\text { current RTE rules }\end{array}$ & $\begin{array}{c}\text { Combination B: best } \\
\text { setting for GIVs }\end{array}$ \\
\hline R1: Minimum Size & N/A & $100 \mathrm{~kW}$ \\
\hline $\begin{array}{l}\text { R2: Possibility to aggregate } \\
\text { across DSOs }\end{array}$ & Possible & Possible \\
\hline R3: Aggregation Level & Not Possible & Telemetry \\
\hline R4: Nature of the remuneration & Regulated & Market-based \\
\hline $\begin{array}{l}\text { R5: Consistency of the remuner- } \\
\text { ation scheme }\end{array}$ & $\begin{array}{l}\text { All grid services } \\
\text { are remunerated }\end{array}$ & $\begin{array}{l}\text { All grid services are } \\
\text { remunerated }\end{array}$ \\
\hline R6: Bonus for extra flexibility & Not existing & $\begin{array}{c}\text { Set at the efficient } \\
\text { level }\end{array}$ \\
\hline
\end{tabular}

\subsection{Comparison of combinations $A$ and $B$ : results}

Under the combination of rules A, GIVs are not allowed to participate in the frequency control market; aggregation of distributed energy resources are not allowed to join in this regulated market. Even if they were, GIV fleets would have a very limited remuneration because: (a) RTE dispatches the reserve among the units based on their historical load share and (b) the payment scheme is a regulated tariff set for long periods of time. Moreover, the minimum bidding amount is rather high, which could prevent early adopters (such as small company fleets) from entering the market.

As for combination of rules B, earnings per power level of charging station are provided in Table 9. Week-end revenues are not reflected in these findings, 
which only cover working days, so the actual GIV remuneration would be more important over one year. Results are much dependent on the EVSE power level, as the remuneration scheme is based on $€ / M W$. A typical GIV owner, with a $3 \mathrm{~kW}$ domestic plug and no EVSE at work could earn $130 € /$ year. On the other side, a GIV owner with a $7 \mathrm{~kW}$ charging station at home and a $22 \mathrm{~kW}$ charging station at work could earn up to $1,448 € /$ year.

Table 9: Average earnings per vehicle and per year depending on the EVSE power level for combination of rules $B$

\begin{tabular}{ccc}
\hline \multicolumn{2}{c}{ EVSE power level $(\mathrm{kW})$} & \\
\cline { 1 - 2 } Primary & Secondary & GIV revenues / year $(€)$ \\
\hline 3 & 0 & 180 \\
3 & 3 & 310 \\
3 & 7 & 505 \\
3 & 22 & 1,346 \\
7 & 0 & 474 \\
7 & 3 & 543 \\
7 & 7 & 780 \\
7 & 22 & 1,448 \\
\hline
\end{tabular}

If the results are averaged per charging station for the entire fleet and for the different scenarios (based on Tables 5 and 6), the average yearly revenues per EV and for each scenario may be computed. Results are featured on Table 10.

Table 10: Average earnings per GIV and per year for each scenario and for combination B

\begin{tabular}{lc}
\hline Scenario & Average yearly GIV revenues $(€)$ \\
\hline Scenario 1 & 149 \\
Scenario 2 & 251 \\
Scenario 3 & 353 \\
Scenario 4 & 456 \\
\hline
\end{tabular}

These expected revenues shed some light on the loss of revenues for GIVs due to the implementation of restrictive TSO rules. Under the combination of rules A, GIVs are merely not allowed to participate in the frequency control regulated 
market (so their revenues amount to 0 ). Under the combination of rules B, they can expect to earn between $193 €$ and $593 €$ a year.

\subsection{Possible future evolutions of the market rules understudied}

In order to anticipate future changes in the rules in Europe, the ENTSO-E network codes (which are still at the draft step) are screened [59, 60, 61, 62, 63]. These documents pave the way for future European TSO regulation. The suggested rules in the network codes are compared with the best combination of rules for GIV fleets that was found in this survey. Results are presented in Table 11.

Table 11: Identified best combination of rules for GIVs compared to ENTSOE guidelines

\begin{tabular}{|c|c|c|}
\hline Rule & $\begin{array}{l}\text { Best Combination of } \\
\text { rules for GIVs }\end{array}$ & ENTSOE Proposals \\
\hline R1: Minimum Size & $100 \mathrm{~kW}$ & Not addressed \\
\hline $\begin{array}{l}\text { R2: Possibility to ag- } \\
\text { gregate across DSOs }\end{array}$ & Possible & $\begin{array}{l}\text { Not clearly defined, but TSOs and } \\
\text { DSOs should make all endeavors and } \\
\text { cooperate in order to ease the partici- } \\
\text { pation to DSR }\end{array}$ \\
\hline Aggregation & Telemetry & $\begin{array}{l}\text { Status of aggregator defined. Teleme- } \\
\text { try aggregation considered for FCR up } \\
\text { to } 1.5 \mathrm{MW}\end{array}$ \\
\hline $\begin{array}{l}\text { R4: Nature of the re- } \\
\text { muneration }\end{array}$ & Market Based & Market Based \\
\hline $\begin{array}{l}\text { R5: Consistency of the } \\
\text { remuneration scheme }\end{array}$ & All AS should be paid & All AS should be paid \\
\hline $\begin{array}{l}\text { R6: Bonus for extra } \\
\text { flexibility }\end{array}$ & $\begin{array}{l}\text { Set at the efficient level / } \\
\text { separate market created }\end{array}$ & DSR VFAPC should be implemented \\
\hline
\end{tabular}

According to this table, ENTSO-E proposals are pushing TSO regulation in the correct direction to enable the participation of GIVs in the TSO reserve markets, although, based on the structure found, it seems that they could go one step further towards the best combination of rules for GIVs. If the future development of the network codes maintain the same approach, the incentives of grid operators, electricity service providers and GIV users should be aligned. Integrated grids need a regulatory framework addressing simultaneously grid services, grid technology innovations and grid users. 


\section{Conclusions}

The presented simulation results show that, under the ideal market design for GIV fleets, GIVs could achieve significant earnings. The Total Cost of Ownership of GIVs could be notably reduced. Obviously, our simulation model is quite simple and does not take into account the myriad of parameters TSOs have to deal with. Still, considering the identified diversity of existing TSO rules, the results indicate possible improvements in the TSO market rules, which are listed below. These possible improvements could be investigated further by each TSO, or by the European association ENTSO-E.

1. A legal framework and a formal status for distributed storage units could be considered in TSO rules. Indeed, in most of the rules that were analyzed, there were no special considerations regarding storage units, which therefore have to abide by both producer and consumer rules and requirements. As a consequence, rules do not seem to be adapted to them yet. For instance, energy costs were not considered in this survey because payments for frequency control are based on availability (€/MW). Nevertheless, because GIVs constantly charge and discharge, it would be much more beneficial for them to be granted net metering. Similarly, compliance tests, ongoing validation procedures, etc. could be defined specifically for storage units, bearing in mind their particular technical characteristics.

2. The rules could ease and encourage the building of coalitions of small distributed units. Such aggregations would have a single entry point from the TSO perspective (even if non-material), which would enable them to dispatch the power flows among the distributed units as they wish, thus maximizing the aggregations' ability to bid in the electricity markets. Moreover, the minimum number of GIV required in the coalition could be kept low in order to foster early adopters and thus technology deployment. Several rules have an impact on the minimum number of GIVs in the aggregation: the minimum bidding amount, which could be kept as low as possible, and the possibility to aggregate GIVs across various Distribution System Operators.

3. All grid services could be remunerated in a fair and transparent manner, so that no grid service would be left unremunerated, as is the case with primary frequency control in some regions today. Adapted markets could be implemented for the provision of all grid services. Markets increase transparency in the sense that they enable participating units to clearly understand the clearing price formation, and the reserve allocation method.The remuneration level should not be discriminatory and, for example, extra bonus for fast ramping units could be considered as a way to incentivize these fleets to provide the services needed. 
The best combination of rules for GIVs provide a roadmap for electricity grids and their regulatory frameworks to evolve towards an efficient grid integration of plug-in vehicles. Both TSOs, because they could take advantage of new efficient reserve providing units, and GIV owners, because they could lower their TCO, would benefit from an evolution of the rules towards the identified best combination for GIVs. The simulation results show that GIV owners could be involved in the process thanks to the financial incentives calculated from the simulations; without customers' involvement, it would not be possible to develop such solutions.

There are several challenges in having TSOs changing their rules towards the identified best combination. First, changing TSO rules is a lengthy process that should be carried out thoroughly. Indeed, TSO costs are reflected in electricity tariffs for end users, thus any change in the rules that could have an impact on electricity bills should be deeply analyzed and validated by the local regulation commission. Any market design correction should not result in other unexpected market disruption. Then, because the priority of TSOs is the security of supply, i.e. to serve all their customers at all times. Considering this fact, some TSOs might be reluctant to change towards rules which could improve competitiveness or sustainability, but whose impact on the security of supply is considered uncertain. Nevertheless, ENTSO-E network codes will come into effect in a near future, and TSOs will have to comply with these new requirements.

Future work could consist in going one step further by conducting a similar analysis on the technical parameters of the frequency market rules. For instance, simulations could provide insights into the relevant market clearing period value (which was arbitrarily set to one hour in this survey) or on whether UP and DOWN products should be procured jointly or separately. Furthermore, the provision of other grid services (such as secondary control, balancing mechanisms, etc.) by GIV fleets could be investigated. Multidisciplinary approaches should be considered, taking into account economics, technical and regulatory aspects.

\section{Acknowledgments}

Paul Codani benefits from the support of the Chair "PSA Peugeot Citroen Automobile: Hybrid technologies and Economy of Electromobility", so-called Armand Peugeot Chair led by CentraleSuplec, and ESSEC Business School and sponsored by PEUGEOT CITROEN Automobile.

We would like to thank the research teams of the GridOnWheels and Nikola projects for their valuable inputs. In particular, the authors gratefully acknowledge the contributions of Willett Kempton (University of Delaware), Bjoern Christensen (Nuvve), Ole Jan Olesen (Nikola project) and Olivier Borne (CentraleSupelec). At 
last, the authors would like to thank Martin Hennebel (CentraleSupelec) for helping with the frequency data set.

\section{References}

[1] International Energy Agency, Global EV Outlook (2013).

URL https://www.iea.org/publications/ globalevoutlook $\left\{\backslash_{-}\right\} 2013$.pdf

[2] Avere, Plus de 22000 véhicules électriques immatricules en france en 2015 !, http://www.avere-france.org/Site/Article/ ?article_id=6424\&from_espace_adherent=0, Last Accessed April $4^{\text {th }}, 2016$ (January 2016).

[3] RTE, Bilan previsionnel de l'equilibre offre-demande d'electricite en France, http://www.rte-france.com/sites/default/ files/bilan_complet_2014.pdf (2014).

[4] Board on Energy and Environmental Systems; Division on Engineering and Physical Sciences; Transportation Research Board, Overcoming Barriers to Electric-Vehicle Deployment, National Academies Press, Washington, D.C., 2013. doi:10.17226/18320.

URL http: / / www. nap.edu/catalog/18320

[5] Commissariat General au Developpement Durable, Les vehicules electriques en perspectives, http://www. developpement-durable.gouv. fr/IMG/pdf / ED 41 .pdf, Last Accessed July st, 2016 (2011).

URL http://www.developpement-durable.gouv.fr/IMG/ pdf/ED $41 \cdot p d f$

[6] W. Kempton, J. Tomić, Vehicle-to-grid power fundamentals: Calculating capacity and net revenue, Journal of Power Sources 144 (1) (2005) 268-279. doi:10.1016/j.jpowsour.2004.12.025.

[7] E. Sortomme, M. a. El-Sharkawi, Optimal Scheduling of Vehicle-to-Grid Energy and Ancillary Services, IEEE Transactions on Smart Grid 3 (1) (2012) 351-359. doi:10.1109/TSG.2011.2164099.

[8] S. Vandael, T. Holvoet, G. Deconinck, S. Kamboj, K. Willett, A comparison of two V2G mechanisms for providing ancillary services at the University of Delaware, in: IEEE International Conference On Smart Grid Communications, IEEE, Vancouver (Canada), 2013, pp. 211 - 216. 
[9] D. Dallinger, D. Krampe, M. Wietschel, Vehicle-to-Grid Regulation Reserves Based on a Dynamic Simulation of Mobility Behavior, IEEE Transactions on Smart Grid 2 (2) (2011) 302-313. doi:10.1109/TSG.2011.2131692.

[10] S. Han, S. Han, K. Sezaki, Economic assessment on V2G frequency regulation regarding the battery degradation, in: 2012 IEEE PES Innovative Smart Grid Technologies, ISGT 2012, 2012. doi:10.1109/ISGT.2012.6175717.

[11] P. Bach Andersen, R. Garcia-Valle, W. Kempton, A comparison of electric vehicle integration projects, in: 2012 3rd IEEE PES Innovative Smart Grid Technologies Europe (ISGT Europe), no. 081216 in 1, IEEE, 2012, pp. 1-7. doi:10.1109/ISGTEurope.2012.6465780.

[12] V. Rious, J.-M. Glachant, Y. Perez, P. Dessante, The diversity of design of TSOs, Energy Policy 36 (9) (2008) 3323-3332. doi:10.1016/j.enpol.2008.05.010.

[13] P. Codani, P. L. L. Portz, P. Claverie, M. Petit, Y. Perez, Coupling local renewable energy production with electric vehicle charging: a survey of the French case, International Journal of Automotive Technology and Management 16 (1) (2016) 55. doi:10.1504/IJATM.2016.076443. URL http: / / www. inderscience.com/link.php?id=76443

[14] H. Fathabadi, Utilization of electric vehicles and renewable energy sources used as distributed generators for improving characteristics of electric power distribution systems, Energy 90 (2015) 1100-1110. doi:10.1016/j.energy.2015.06.063.

URL http://linkinghub.elsevier.com/retrieve/pii/ S0360544215008191

[15] M. Carrión, R. Zárate-Miñano, Operation of renewable-dominated power systems with a significant penetration of plug-in electric vehicles, Energy 90 (2015) 827-835. doi:10.1016/j.energy.2015.07.111.

URL http://linkinghub.elsevier.com/retrieve/pii/ S0360544215010063

[16] P. Codani, M. Petit, Y. Perez, Participation of an Electric Vehicle fleet to primary frequency control in France, International Journal of Electric and Hybrid Vehicles 7 (3). doi:10.1504/IJEHV.2015.071639.

[17] Energinet.dk, Ancillary services to be delivered in Denmark Tender conditions, https://www.energinet.dk/ SiteCollectionDocuments/Engelske20dokumenter/ 
$\mathrm{El} / 8871-11 \% 20 \mathrm{v} 3 \% 20 \mathrm{Ancillary} \div 20$ services\%20to\%

20 be $\% 20$ delivered $\% 20$ in $\% 20$ Denmark $\div 20-\frac{\circ}{2} 20$ Tender $\%$

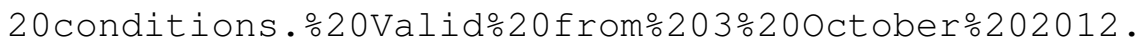
pdf (2012).

[18] Reseaux de Transport d'Electricite, Mémento de la sûreté du système électrique, https://eco2mix.rte-france.com/uploads/ media/pdf_zip/publications-annuelles/memento_ surete_2004_complet_.pdf (2004).

[19] Reseaux de Transport d'Electricite, Documentation Technique de Référence Chapitre 4.1 - Contribution des utilisateurs aux performances du RPT, http://clients.rte-france.com/htm/fr/mediatheque/ telecharge/reftech/30-06-05_article_4-8_v1.pdf (2011).

[20] Reseaux de Transport d'Electricite, Documentation technique de référence Article 8.10: Modèle de contrat de participation aux services système (2011). URL http: / /www.rte-france.com/uploads / Mediatheque $\left\{\backslash_{-}\right\}$docs/offres $\left\{\backslash_{-}\right\}$services/reftech/ 03-02-11\{\_\}complet.pdf

[21] Electric Reliability Council of Texas, Nodal Protocols Section 8: Performance Monitoring, http://www.ercot.com/mktrules/ nprotocols/current (2012).

[22] Electric Reliability Council of Texas, Nodal Protocols Section 6: Adjustment Period and Real-Time Operations, http: //www.ercot.com/ mktrules/nprotocols/current (2013).

[23] Electric Reliability Council of Texas, Nodal Protocols Section 4: Day-Ahead Operations, http://www.ercot.com/mktrules/nprotocols/ current (2013).

[24] Electric Reliability Council of Texas, Nodal Protocols Section 3: Management Activities for the ERCOT System, http://www.ercot.com/ mktrules/nprotocols/current (2013).

[25] Electric Reliability Council of Texas, Nodal Protocols Section 16: Registration and Qualification of Market Participants, http: / /www . ercot.com/ mktrules/nprotocols/current (2013). 
[26] California Independent System Operator, Rules for net metering (2013).

URL http://www.dsireusa.org/incentives/incentive. cfm? Incentive $\left\{\backslash_{-}\right\}$Code $=$CA02R

[27] California Independent System Operator, Tariff Clarifications to Implement Pay for Performance Regulation, http://www.caiso.com/Documents/ TariffClarifications-ImplementPay-PerformanceRegulation. pdf, Last Accessed July 1 ${ }^{\text {st }}, 2016$ (2013).

URL http://www.caiso.com/Documents/ TariffClarifications-ImplementPay-PerformanceRegulation. pdf

[28] California Independent System Operator, Non-Generator Resources - Regulation Energy Management - Frequently Asked Questions, https://www.caiso.com/Documents/FrequentlyAskedQuestionsNonGeneratorResourceRegulationEnergyManagementMarketSimulation.pdf (2011).

URL Jurlihttps://www.caiso.com/Documents/

FrequentlyAskedQuestions-NonGeneratorResourceRegulationEnergyManagement pdf \}

[29] California Independent System Operator, Proposal for participation of nongenerator resources in California ISO ancillary services markets, http: // www. caiso.com/246f/246fb968171e0.pdf (2009).

[30] PJM Interconnection, Manual 1: Control Center and Data Exchange Requirements, http://www.pjm.com/ /media/documents/manuals/ m01. $\operatorname{ashx}(2013)$.

[31] PJM Interconnection, Manual 10: Pre-Scheduling Operations, https : / / www.pjm.com/ /media/documents/manuals/m10.ashx (2013).

[32] PJM Interconnection, Manual 11 : Energy \& Ancillary Services, http: / / www.pjm.com/ /media/documents/manuals/m11.ashx (2013).

[33] PJM Interconnection, Manual 12: Balancing Operations, http://www . pjm.com/ /media/documents/manuals/m12.ashx (2012).

[34] National Grid, Balancing code 3: Frequency control process, http: //www2.nationalgrid.com/uk/industry-information/ electricity-codes/grid-code/the-grid-code/, Last Accessed April $4^{\text {th }}, 2016$ (2012). 
[35] National Grid, CUSC - Section 4 Balancing Services, http: //www2.nationalgrid.com/uk/industry-information/ electricity-codes/cusc/the-cusc/, Last Accessed April $4^{\text {th }}$, 2016 (2012).

[36] National Grid, Grid Code Chapter 06 - Connection conditions, http: //www2.nationalgrid.com/uk/industry-information/ electricity-codes/grid-code/the-grid-code/, Last Accessed April $4^{\text {th }}, 2016$ (2013).

[37] GridOnWheels project, Gridonwheels project webpage, http: //grid-on-wheels. com, Last Accessed July 1 ${ }^{\text {st }}, 2016$ (2016).

URL http://grid-on-wheels.com/

[38] Nikola project, Nikola project webpage, http://www.nikola. droppages . com/, Last Accessed April 30 ${ }^{\text {th }}, 2016$ (2016).

URL http: / /www.nikola.droppages.com/

[39] S. Kamboj, W. Kempton, K. S. Decker, Deploying Power Grid-Integrated Electric Vehicles as a Multi-Agent System, 10th Int. Conf. on Autonomous Agents and Multiagent Systems - Innovative Applications Track (AAMAS) 1 (Aamas) (2011) 2-6.

[40] E. Koliou, C. Eid, J. P. Chaves-Ávila, R. a. Hakvoort, Demand response in liberalized electricity markets: Analysis of aggregated load participation in the German balancing mechanism, Energy 71 (2014) 245-254. doi:10.1016/j.energy.2014.04.067.

URL http://linkinghub.elsevier.com/retrieve/pii/ S0360544214004800

[41] K. Knezovic, M. Marinelli, P. Codani, Y. Perez, Distribution grid services and flexibility provision by electric vehicles: A review of options, in: 2015 50th International Universities Power Engineering Conference (UPEC), IEEE, Staffordshire (UK), 2015, pp. 1-6. doi:10.1109/UPEC.2015.7339931. URL http://ieeexplore.ieee.org/lpdocs/epic03/ wrapper.htm? arnumber $=7339931$

[42] Electric Power Research Institute, The Integrated Grid, Tech. rep., Electric Power Research Institute, http://www.epri.com/Our-Work/ Pages/Integrated-Grid.aspx (2014).

URL http://energy.gov/sites/prod/files/2015/03/f20/ EPRIIntegratedGrid021014.pdf 
[43] R. Raineri, S. Rios, D. Schiele, Technical and economic aspects of ancillary services markets in the electric power industry : an international comparison, Energy Policy 34 (1010750) (2006) 1540-1555. doi:10.1016/j.enpol.2004.11.015.

[44] J. W. Ingleson, S. Member, E. Allen, D. E. Interconnection, A. Beta, Tracking the Eastern Interconnection Frequency Governing Characteristic, Power and Energy Society General Meeting 2010 IEEE (2009) 1-6.

[45] FERC, Order 755 - Frequency Regulation Compensation in the Organized Wholesale Power Markets, https://www.ferc.gov/whats-new/ comm-meet/2011/102011/E-28.pdf (2011).

[46] P. B. Andersen, M. Marinelli, O. J. Olesen, C. A. Andersen, G. Poilasne, B. Christensen, O. Alm, The Nikola project intelligent electric vehicle integration, in: IEEE PES Innovative Smart Grid Technologies, Europe, IEEE, 2014, pp. 1-6. doi:10.1109/ISGTEurope.2014.7028765.

URL http://ieeexplore.ieee.org/lpdocs/epic03/ wrapper.htm?arnumber $=7028765$

[47] Yu Chen, Zhao Xu, J. Ostergaard, Frequency analysis for planned islanding operation in the Danish distribution system - Bornholm, in: 2008 43rd International Universities Power Engineering Conference, IEEE, 2008, pp. 1-5. doi:10.1109/UPEC.2008.4651467.

URL http://ieeexplore.ieee.org/lpdocs/epic03/ wrapper.htm?arnumber $=4651467$

[48] W. Kempton, V. Udo, K. Huber, K. Komara, S. Letendre, S. Baker, D. Brunner, N. Pearre, A Test of Vehicle-to-Grid ( V2G ) for Energy Storage and Frequency Regulation in the PJM System, Tech. rep. (2009).

URL http://www.udel.edu/V2G/resources/ test-v2g-in-pjm-jan09.pdf

[49] Y. G. Rebours, D. S. Kirschen, M. Trotignon, A Survey of Frequency and Voltage Control Ancillary Services Part I : Technical Features, IEEE Transactions on Power Systems 22 (1) (2007) 350-357.

[50] Y. G. Rebours, D. S. Kirschen, M. Trotignon, A Survey of Frequency and Voltage Control Ancillary Services Part II : Economic Features, IEEE Transactions on Power Systems 22 (1) (2007) 358-366.

[51] Reseaux de Transport d'Electricite, RTE Frequency Data Set, Webpage, https://clients.rte-france.com/lang/fr/visiteurs/ 
vie/vie_frequence.jsp, Last Accessed July $1^{\text {th }}, 2016$ (2016).

URL https://clients.rte-france.com/lang/fr/ visiteurs/vie/vie_frequence.jsp

[52] I. Bloom, B. Cole, J. Sohn, S. Jones, E. Polzin, V. Battaglia, G. Henriksen, C. Motloch, R. Richardson, T. Unkelhaeuser, D. Ingersoll, H. Case, An accelerated calendar and cycle life study of Li-ion cells, Journal of Power Sources 101 (2) (2001) 238-247. doi:10.1016/S0378-7753(01)00783-2.

[53] I. Fernández, C. Calvillo, A. Sánchez-Miralles, J. Boal, Capacity fade and aging models for electric batteries and optimal charging strategy for electric vehicles, Energy 60 (2013) 35-43. doi:10.1016/j.energy.2013.07.068.

[54] Cross-border Mobility for EVs, Online publications, http://crome. forschung.kit.edu/francais/57.php (2013). URL http: / / crome.forschung.kit.edu/francais/57.php

[55] S. Izadkhast, P. Garcia-Gonzalez, P. Frias, An Aggregate Model of Plug-In Electric Vehicles for Primary Frequency Control, IEEE Transactions on Power Systems 30 (3) (2015) 1475-1482. doi:10.1109/TPWRS.2014.2337373.

URL http://ieeexplore.ieee.org/lpdocs/epic03/ wrapper.htm?arnumber $=6871408$

[56] CGDD, La mobilité des Français, panorama issu de l'enquête nationale transports et déplacements 2008., http://www. developpement-durable.gouv.fr/IMG/pdf/Rev3.pdf,

Last Accessed July ${ }^{\text {st }}, 2016$ (2010).

URL http://www.developpement-durable.gouv.fr/IMG/ $\mathrm{pdf} / \mathrm{Rev} 3 \cdot \mathrm{pdf}$

[57] Union for the Co-ordination of Transmission of Electricity, Operation Handbook, Tech. Rep. June, Union for the Co-ordination of Transmission of Electricity (2004).

URL www.pse.pl/uploads/kontener/542UCTE_Operation_ Handbook.pdf

[58] Energinet.dk, Energinet.dk market clearing prices, http://energinet. dk/EN/El/Engrosmarked/Udtraek-af-markedsdata/Sider/ default.aspx (2013).

URL http://energinet.dk/EN/El/Engrosmarked/ Udtraek-af-markedsdata/Sider/default.aspx 


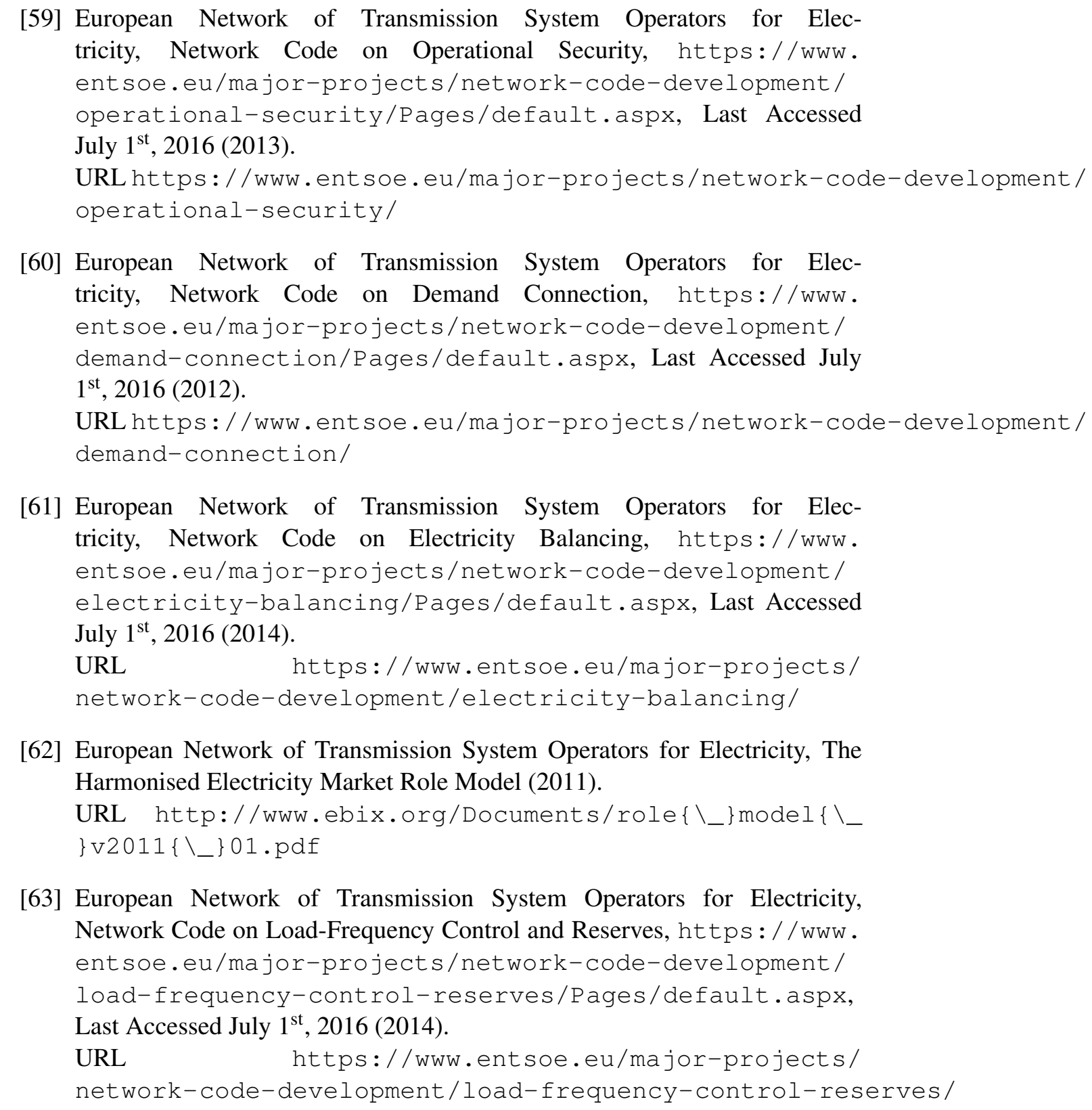

[59] European Network of Transmission System Operators for Electricity, Network Code on Operational Security, https://www. entsoe.eu/major-projects/network-code-development/ operational-security/Pages/default.aspx, Last Accessed July $1^{\text {st }}, 2016$ (2013).

URL https://www.entsoe.eu/major-projects/network-code-development/ operational-security/

[60] European Network of Transmission System Operators for Electricity, Network Code on Demand Connection, https://www . entsoe.eu/major-projects/network-code-development/ demand-connection/Pages/default.aspx, Last Accessed July $1^{\text {st }}, 2016$ (2012).

URL https: / /www.entsoe.eu/major-projects/network-code-development/ demand-connection/

[61] European Network of Transmission System Operators for Electricity, Network Code on Electricity Balancing, https://www. entsoe.eu/major-projects/network-code-development/ electricity-balancing/Pages/default.aspx, Last Accessed July $1^{\text {st }}, 2016$ (2014).

URL https://www.entsoe.eu/major-projects/ network-code-development/electricity-balancing/

[62] European Network of Transmission System Operators for Electricity, The Harmonised Electricity Market Role Model (2011).

URL http://www.ebix.org/Documents/role $\left\{\backslash_{-}\right\}$model $\left\{\backslash_{-}\right.$ \} v2011\{\_\}01.pdf

[63] European Network of Transmission System Operators for Electricity, Network Code on Load-Frequency Control and Reserves, https : / www . entsoe.eu/major-projects/network-code-development/ load-frequency-control-reserves/Pages/default.aspx, Last Accessed July 1 ${ }^{\text {st }}, 2016$ (2014).

URL https://www.entsoe.eu/major-projects/ network-code-development/load-frequency-control-reserves / 